\title{
Teaching for Transfer through Engineering Design
}

\author{
Fred J. Figliano and Gina J. Mariano \\ Troy University, ffigliano, gjmariano@troy.edu
}

\begin{abstract}
This document outlines a qualitative study with the aim of fostering the transfer of Science, Technology, Engineering, and Math (STEM) content while working through engineering design problems. Teaching for transfer offers a vehicle to foster the transfer of STEM content through the abstraction of knowledge in each individual discipline. Many theoretical approaches to explaining knowledge transfer are rooted in a belief that knowledge becomes generalizable through its abstraction. This study used a case study design. Student participants in this study were engaged in pre-engineering design-based activities and ranged from freshman to seniors. This study also took place in a low-income school district that has a high minority population. This group of students allowed for a unique lens, which looked at underrepresented groups and their experience with engineering design. Data were collected through the use of a design log. Student work was aligned with teaching for transfer lessons to identify whether the instruction was fostering the transfer of STEM content. Preliminary findings indicate that when students are overtly made aware of STEM content connections they understand how each discipline can work together to solve a real world problem. Findings such as these have broad applications for curriculum development in the future. If teachers have the tools to teach for transfer and train students how to transfer knowledge they will be better equipped to solve more complex engineering design problems as they get older.
\end{abstract}

Index Terms - Integration, Integrative STEM Education, K12 engineering education, Knowledge Transfer.

\section{INTRODUCTION}

Science, Technology, Engineering, and Mathematics (STEM) literacy is a critical component of 21 st century education [1][2][13][18]. The need for a STEM literate population provides the basis for America's current educational reform agenda. The central tenet of STEM literacy is the preparation of people who are knowledgeable of the connections between the content and practices of the STEM fields. This is in contrast to the silo method of education, which teaches the STEM disciplines independently of each other. When conceived as an integrative curriculum model designed around teamwork and problem-solving environments, Integrative STEM education is the ideal pathway for achieving STEM literacy [21][23][26].
The foundation of Integrative STEM education is design based problems. The pedagogies of technology education and engineering education utilize a design process to bring science, technology, engineering, and mathematics together in concert to solve real-world problems. This technological/engineering $(\mathrm{T} / \mathrm{E})$ design process has strong potential for application in bringing STEM concepts together to solve real-world problems [22][23][25]-[29]. Throughout the $\mathrm{T} / \mathrm{E}$ design process, there are many opportunities for students to use the knowledge learned in one discipline and apply it to the problems presented in another. For example, if a student is trying to design a bridge he/she needs to have some understanding of forces, which is knowledge learned in physics. The student would also need to understand how to apply mathematical calculations to help solve this problem. This process of activating knowledge gained in one context and used in another is "knowledge transfer." A traditional definition of knowledge transfer is "the ability to apply knowledge or use knowledge from one problem, situation or context to another" [3]. Although Anderson's definition is a broad understanding of knowledge transfer, other researchers have taken a more specific approach to its study. Many theoretical approaches to explaining knowledge transfer are rooted in a belief that knowledge becomes generalizable through its abstraction. Reed, Ernst, and Banerji [20] and Gick and Holyoak [10][11] hypothesized that the construction of abstract rules, schemata, or other mental representations serve as the primary cognitive support for knowledge transfer. Other theorists in the field also support the belief that abstractions are mental representations of knowledge transfer [4][7]-[9][19][24]. By theorizing there is a connection between abstractions and the transfer of knowledge, it is possible to develop studies to substantiate this connection. Requisite of any such study would be operationalizing what constitutes a connection. Therefore, for this study the operationalized version of Anderson's definition of knowledge transfer was the abstraction of any knowledge, information, or experiences by participants and used when trying to understand higher order concepts. The $\mathrm{T} / \mathrm{E}$ design process is uniquely suited to foster knowledge transfer because knowledge from different content areas provides the foundation of solving real-world problems.

\section{RESEARCH DESIGN}

The purpose of this study was to begin to understand the impact of overtly teaching for transfer on students learning Science, Technology, Engineering, and Mathematics (STEM) content while working through engineering design 
problems. Teaching for transfer offers a vehicle to foster the transfer of STEM content through the abstraction of knowledge in each individual discipline.

The overarching methodology used in this study was Qualitative. "Qualitative data are a source of well-grounded, rich descriptions and explanations of human processes" [17]. The conduct of this research follows a case study design, specifically a multiple case: embedded design. Engineering design teams comprise the cases in this study and individual students in each team comprise the embedded unit of analysis [30]. For example, if two teams were being studied then they would each be one case. Individual students in each case would be the embedded unit of analysis. A case is embedded when collecting and analyzing data from each participant (unit of analysis) in each case [31].

\section{PARTICIPANTS}

The nature of this study required the participation of individuals involved in pre-engineering design-based activities at the secondary level. There were 20 students engaging in pre-engineering design-based activities participating in this study. Those students ranged from freshman to seniors. This study took place in a low-income school district that has a high minority population. This group of students allowed for a unique lens, which looked at underrepresented groups and their experience with engineering design.

\section{DATA COLLECTION \& ANALYSIS}

Data were collected through the use of a design log. Student work was aligned with teaching for transfer lessons to identify whether the instruction was fostering the transfer of STEM content. Data collection occurred at each work session by providing time for participants to make a Design Log entry. Participants had five to ten minutes to reflect and make their entry.

After each work session, data were analyzed and coded for potential instances of transfer. An operational definition would provide consistent coding of potential instances of knowledge transfer. For this study knowledge transfer was defined as the abstraction of any knowledge, information, or experiences by participants and used when trying to understand higher order concepts. Based on the review of literature, this definition operationalized data analysis [4][12][14]-[16][19][20][24]. To provide a consistent interpretation of terms, the researchers will explain each component of the knowledge transfer definition. Knowledge is what participants understand about a topic learned in a formal educational environment. Information is knowledge that participants do not yet possess, and which is gained through research or talking to content experts of the desired information. Experiences are those real-world, informal learning instances where participants apply knowledge learned while working through some task. Participants pull from these three areas when trying to understand higher order concepts. Participants understand higher order concepts by first understanding the lower level cognitive knowledge associated with that larger concept [5]. This way of building cognitive knowledge allows participants to come to understand higher-level cognitive concepts.

As previously discussed, abstractions are representations of knowledge transfer. Abstractions serve as the primary cognitive support for knowledge transfer [4][7]-[9][19][24]. The Design Log allows researchers to make judgments of potential instances of knowledge transfer during T/E design activities. The researcher identified abstractions from the data as the primary mechanism of identifying potential instances of transfer. The researcher used the operational definition for knowledge transfer to analyze Design Log entries for points of abstraction.

Data analysis began with the review of Design Log entries. The purpose of this review was to identify abstractions. When an abstraction was identified, the verbatim Design Log entry provided by participants was entered into the analysis rubric along with the reflective prompt that it occurred in and the individual participant reporting the abstraction. Data allowed the researcher to make an inference regarding how participants used the abstraction. The purpose of using the analysis rubric was to display data in preparation to make judgments regarding whether or not each abstraction was an instance of STEM content knowledge transfer.

\section{FINDINGS \& CONCLUSIONS}

Preliminary findings indicate that when students are overtly made aware of STEM content connections they understand how each discipline can work together to solve a real world problem. Findings such as these have broad applications for curriculum development in the future. If teachers have the tools to teach for transfer and train students how to transfer knowledge they will be better equipped to solve more complex engineering design problems as they get older.

The illustration of the transfer paradigm (abstraction + situated environments $=$ transfer) depicted in this study builds on previous transfer research and goes a step further to specifically look at transfer in a combined $\mathrm{T} / \mathrm{E}$ design process. Studies, such as the one discussed here, help to validate this perspective. $\mathrm{T} / \mathrm{E}$ design provided a unique lens as the context for this study and allowed the researchers to take previous work and utilize it in a novel situation. From this investigation, the researchers found the T/E design process to be an ideal context for studying the transfer of knowledge because T/E design inherently requires students to use knowledge learned from many disciplines to solve design problems.

\section{REFERENCES}

[1] American Association for the Advancement of Science (1989). Science for All Americans. New York: Oxford University Press. 
[2] American Association for the Advancement of Science (1993). Benchmarks for science literacy. New York: Oxford University Press.

[3] Anderson, J.R. (2005). Cognitive psychology and its implications. New York: Worth.

[4] Fuchs, L. S., Fuchs, D., Prentice, K., Burch, M., Hamlett, C. L., Owen, R., et al. (2003). Explicitly teaching for transfer: Effects on third-grade students' mathematical problem solving. Journal of Educational Psychology, 95(2), 293-305.

[5] Gagne, R. M., Wager, W. W., Golas, K. C., and Keller, J. M. (2005). Principles of instructional design. Wadsworth, Cengage Learning.

[6] Gagne, R. M. \& Paradise, N. E. (1961). Abilities and learning sets in knowledge acquisition. Psychological Monographs: General and Applied, 75(518).

[7] Gentner, D., Loewenstein, J.,\&Thompson, L. (2003). Learning and transfer: A general role for analogical encoding. Journal of Educational Psychology, 95(2), 393-408.

[8] Gentner, D., \& Markman, A. B. (1997). Structure mapping in analogy and similarity. American Psychologist, 52, 45-56.

[9] Gentner, D., \& Medina, J. (1998). Similarity and the development of rules. Cognition, 65, 263-297.

[10] Gick, M. L., \& Holyoak, K. J. (1980). Analogical problem solving. Cognitive Psychology, 12, 306-355.

[11] Gick, M. L., \& Holyoak, K. J. (1983). Schema induction and analogical transfer. Cognitive Psychology, 15, 1-38

[12] Gick, M. L. \& Holyoak, K. J. (1987). The cognitive basis of knowledge transfer. In S. M. Cormier \& J. D. Hagman (Eds.). Transfer of Learning: Contemporary research and application. San Diego, CA: Academic Press.

[13]International Technology Education Association (2000). Standards for technological literacy: Content for the study of technology. Reston, VA: ITEA.

[14] Lobato, J. (2006). Alternative perspectives on the transfer of learning: History, issues, and challenges for future research. The Journal of the Learning Sciences, 15(4), 431-449.

[15] Lobato, J. (2003). How design experiments can inform a rethinking of transfer and vice versa. Educational Researcher, 32(1), $17-20$.

[16] Lobato, J. (1997). Transfer reconceived: How "sameness" is produced in mathematical activity. Unpublished doctoral dissertation, University of California, Berkeley.

[17]Miles, M. B., Huberman, A. M. \& Saldana, J. (2014). Qualitative data analysis. London, UK: SAGE Publications Ltd.

[18]National Council of Teachers of Mathematics (2000). Principles and standards for school mathematics. VA: NCTM.

[19] Reed, S. K. (1993). A schema-based theory of transfer. In D. K. Detterman \& R. J. Sternberg (Eds.), Transfer on trial: Intelligence, cognition, and instruction (pp. 39-67). Norwood, NJ: Ablex.

[20] Reed, S. K., Ernst, G. W., \& Banerji, R. (1974). The role of analogy in transfer between similar problem states. Cognitive Psychology, 6, 436-450.

[21]Sanders, M. (2008, December). STEM, STEM education, STEMmania. The Technology Teacher, December, 2008.

[22] Sanders, M. E. (2007). EDCI 5774 STEM education trends and issues. Virginia Tech, Blacksburg, VA.

[23]Sanders, M. (2006, November). A rationale for new approaches to STEM education and STEM education graduate programs. Paper presented at the $93^{\text {rd }}$ Mississippi Valley Technology Teacher Education Conference, Nashville, TN.

[24] Singley, M. K.,\&Anderson, J. R. (1989). The transfer of cognitive skill. Cambridge, MA: Harvard University Press.

[25] Wells, J. (2010). Research on teaching and learning in science education: Potentials for technology education. In P. Reed \& J. LaPorte (Eds.), Research in Technology Education (pp. 182-202). Council on Technology Teacher Education. Reston, VA: ITEA.

[26]Wells, J. (2008, November). STEM Education: The potential of technology education. Paper presented at the $95^{\text {th }}$ Mississippi Valley Technology Teacher Education Conference, St. Louis, MI.

[27] Wells, J. (2007a). EDCI 5774 Biotechnology literacy: PBL activities. Virginia Tech, Blacksburg, VA.

[28] Wells, J. (2007b). EDCI 5774 STEM education research. Virginia Tech, Blacksburg, VA.
[29] Wells, J. (2006). EDCI 5774 STEM education pedagogy. Virginia Tech, Blacksburg, VA.

[30]Yin, R. K. (2009) Case study research: Design and methods fourth edition. Thousand Oaks, CA: SAGE Publications.

[31]Yin, R. K. (2003) Case study research: Design and methods third edition. Thousand Oaks, CA: SAGE Publications.

\section{COPYRIGHT FORM}

We will use the IEEE electronic copyright form.

\section{AUTHOR INFORMATION}

Fred J. Figliano, Assistant Professor, Division of Education, Troy University.

Gina J. Mariano, Assistant Professor, Division of Psychology, Troy University. 